\title{
Study of the Multi-Airport Ground-holding Strategy Model and Application
}

\author{
Xiushan Jiang ${ }^{1, \text { a }}$, Yingyi Xie ${ }^{2, b}$ and Xifeng $\mathrm{Li}^{3, \mathrm{C}}$ \\ 1, 2 School of Traffic and Transportation, Beijing Jiaotong University, Beijing 100044, China \\ ${ }^{3}$ Beijing Metro communications Signal Companies, Beijing 100044, China \\ a xshjiang@bjtu.edu.cn, b15125800@bjtu.edu.cn
}

Keywords: multi-airport ground-holding strategy, model, optimization, algorithm.

Abstract. One of the effective methods in air traffic flow management is ground holding. The Air Ground-holding Strategy can effectively alleviate the air congestion and reduce delays by switching air waiting to ground waiting. This paper use the minimum total cost as the target and the limit of integrated capacity as constraints, built multi-airport ground-holding strategy model based on the priority ranking of flights. We put forward a solution algorithm, the efficacious of the model is justified through analyzing the data of Beijing capital Airport, Shanghai Hongqiao Airport and Guangzhou Baiyun Airport, optimize the flight schedule, and solve the problems of flight delay.

\section{Introduction}

Flight conflict, flight delays, traffic congestion and other problems are becoming increasingly prominent due to the limited airport capacity, which not only cause passenger inconvenience, but also give rise to economic losses to airlines and seriously affects the safety of airports and airspace in China. Air Ground-holding Strategy can effectively ease air congestion and reduce flight delays. Many scholars ${ }^{[1]}$ have made contributions to the application of ground-holding strategy by studying single airport ground-holding and static multi-airport ground-holding. Odoni ${ }^{[2]}$ study the single airport in detail. Brunetta et al ${ }^{[3-7]}$ propose flight priority rules, considering the different delay costs of flight and propose a cost function based on flight priority. Ravizza et al. ${ }^{[8]}$ analyze the data of European hub airport, and put forward the sequence diagram algorithm to reduce delay cost, fuel cost and pollution cost. Other scholars ${ }^{[9-10]}$ propose multi-objective, multi airport air traffic management model, considering the influence of airport network delays accumulated benefits and consecutive voyages flights, and use the methods of ground-holding and canceled flights, achieve the rational allocation of airport capacity and reduce flight delays.

In this paper, we establish the function model, which is conducive to solve practical problems of civil aviation of China to minimize the total cost, with constraint of the airport capacity, priority of the flying rules, and under consideration of the ground holding cost and flight delays cost. The outline of this paper is as follows. Section 1 is the literature review. Section 2 proposes model building. Section 3 describes the data used in a case study. Section 4 provides a brief conclusion and outlook for future research.

\section{Methodology}

The model mainly considers the constraints of the airport capacity and the priority of the flight with the target of minimizing the total cost and flight delays.

Assumptions of the model:

a. The limit of the airport capacity is the only limiting factor of congestion

b. The airport capacity of the model is the integrated capacity because the airport runways are for both taking off and landing in China.

Assume $\mathrm{m}$ flights $f_{i}(i=1, \ldots, m)$ take off from airport in the closed network of airport, land at destination airport $\mathrm{z}$. The flight $f_{i}^{\prime}$ is a continuous flight which takes off at the airport $\mathrm{z}$ to other airports in the network after landing at airport z. The model is shown in Figure 1. 


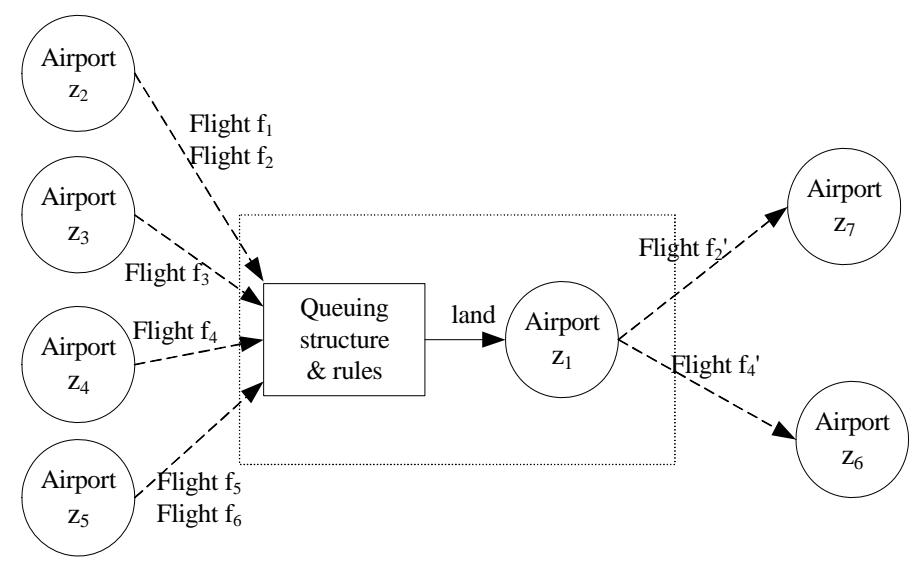

Figure1: The model figure of Multi-airport Ground-Holding

Let $\mathrm{z}$ be the airport sequence of length $\mathrm{n}$; divided the busiest time of a day $\mathrm{T}$ into $\mathrm{t}$ slice in 5 minutes interval, $\mathrm{T}$ for time series, the length is $5 \mathrm{t} . \mathrm{K}\left(z_{i}\right) z_{i} \in z$ is the maximum security capacity of the airport In airport $z$, a taking off or landing flight $\mathrm{F}(\mathrm{t}, \mathrm{z})$ in $\mathrm{t}$ time, $x_{f t}$ is the decision variables, $x_{f t}=1$ if the flight $f$ off or landing in t time; otherwise, $x_{f t}=0$.

In t time, the number of takeoff and landing flight should be less than the maximum guarantee capacity, that is:

\section{$\sum_{f \in \mathrm{F}(\mathrm{t}, \mathrm{z})} x_{f t} \leq \mathrm{K}(\mathrm{z})$}

If the number of flights exceeds this capacity, we need to implement ground holding to some flights. The principal of flight as follows: day.

(1) Continuous flight priority principle. Continuous flight has more than one flight mission in a

(2) Priority of flight delays principle: the flight schedule for more than 15 minutes of waiting time is scheduled to take off in priority in order to reduce the rate of flight delay.

(3) High frequency flight priority principle.

(4) Large aircraft priority principle.

The total cost of the ground waiting strategy includes the cost of the flight to the airport ground and the cost of the delay in the flight.

Set the waiting timet $f g$ to the ground-holding of the flight $\mathrm{f}$, and $\mathrm{u}_{f g}$ is the decision variables, so that

$$
u_{f p}= \begin{cases}\sum_{t \in T} t x_{f t}-r_{f}-3 & \sum_{t \in T} t x_{f t}-r_{f}-3>0 \\ 0 & \sum_{t \in T} t x_{f t}-r_{f}-3 \leq 0\end{cases}
$$

Set $s_{f_{1} f_{2}}$ is the maximum ground-holding time when flight $f_{1}$ does not affect the normal flight takeoff and not exceed the longest waiting time. The flight is performed by the same frame aircraft flight of subsequent flights.

Other symbols used in the model are shown in table 1.

Table1: Symbol index

\begin{tabular}{|c|l|c|l|}
\hline $\begin{array}{c}\text { Symbol } \\
\text { name }\end{array}$ & \multicolumn{1}{|c|}{ notes } & $\begin{array}{c}\text { Symbol } \\
\text { name }\end{array}$ & \multicolumn{1}{|c|}{ notes } \\
\hline $\mathrm{T}$ & Time slice sequence & $a_{f}$ & Departure time of flight $\mathrm{f}$ \\
\hline $\mathrm{t}$ & A series of time slice & $r_{f}$ & Landing time of flight $\mathrm{f}$ \\
\hline $\mathrm{F}$ & Flight sequence & $C_{f}^{\mathrm{g}}$ & Ground-holding cost coefficient for flight $\mathrm{f}$ \\
\hline
\end{tabular}




\begin{tabular}{|c|l|c|l|}
\hline $\mathrm{f}$ & Flights in Flight sequence & $C_{f}^{\mathrm{p}}$ & Delay cost coefficient for flight $\mathrm{f}$ \\
\hline $\mathrm{Z}$ & Airport sequence & $G_{f}$ & Maximum ground waiting time of flight $\mathrm{f}$ \\
\hline $\mathrm{z}$ & Airports in airport sequence & $T_{f}$ & Time flight $\mathrm{f}$ may land \\
\hline$K_{Z}$ & Maximum security capacity of airport $\mathrm{Z}$ & & \\
\hline
\end{tabular}

According to the above analysis, the multi airport ground-holding strategy optimization model is as follows:

Objective function:

$$
\operatorname{Min} \sum_{f \in F}\left[c_{f}^{g}\left(\sum_{t \in T_{f}} t x_{f t}-r_{f}\right)+c_{f}^{p} u_{f p}\right]
$$

Constraint conditions:

$$
\begin{aligned}
& \sum_{f \in F(t, f)} x_{f t} \leq K(z) \quad z \in Z \\
& \sum_{t \in T_{f}} x_{f t}=1 \quad f \in F \\
& \sum_{t \in T_{f}} t x_{f_{1} t}-r_{f_{1}}-s_{f_{1} f_{2}} \leq \sum_{t \in T_{f}} t x_{f_{2} t}-r_{f_{2}} \\
& u_{f p}= \begin{cases}\sum_{t \in T_{f}} t x_{f t}-r_{f}-3 & \sum_{t \in T} t x_{f t}-r_{f}-3>0 \\
0 & \sum_{t \in T} t x_{f t}-r_{f}-3 \leq 0\end{cases} \\
& x_{f t} \in\{0,1\}
\end{aligned}
$$

Formula (1) is the objective function of the model, and the ground waiting cost and delay cost of all flights are the minimum; (2) for the capacity constraints, ensure the number of flights within the maximum capacity of the airport in t time; (3) state constraints for the flight, flight $f$ should take off or land only one time in take-off or landing time slice;(4) ensure implementation of continuous flight of the aircraft in the execution of the subsequent flight when the previous flight has landed; (5) is discriminant constraints of delay cost, regardless of the cost when ground-holding time less than three time slices; (6) represent that if flights land or not.

\section{Data and Case Study}

Multi airport ground-holding strategy model considers airport comprehensive capacity constraints and delay costs, in this paper, the optimization of Beijing Capital Airport, Shanghai Hongqiao Airport and Guangzhou Baiyun Airport was proposed to solve the problem of flight delays and put forward the solution algorithm of multi-airport ground waiting model based on flight priority.

i) Before optimization:

There are a total of 81 flight landing at Beijing Capital Airport, which normal flight have 57 aircraft, accounted for $70.4 \%$ of the total number of flights, delayed flights of 24 aircraft, accounted for 29.6\%; take-off flights for a total of 83 frame, which normal flight have 34 frame, accounted for $4.1 \%$ of the total number of flights, delayed flights of 24 aircraft, accounted for $59.0 \%$.

Shanghai Hongqiao airport landing a total of 48 flight, which normal flight have 34 aircraft, accounting for $70.8 \%$ of the total number of flights, delayed flight 14 , accounting for $29.2 \%$; take-off flights for a total of 58 Airbus, which normal flight have 37 aircraft, accounting for 68.3\% of the total number of flights, delayed flight 21, accounting for $36.2 \%$.

Guangzhou Baiyun airport landing flight for a total of 63 frame, which normal flight have 37 
aircraft, accounted for $58.7 \%$ of total number of flights, delayed flight 26 , accounting for $41.3 \%$; take-off flights for a total of 84 flight, which normal flight have 50 aircraft, accounting for $59.5 \%$ of the total number of flights, flight delay has 34 frame, accounted for $40.5 \%$.

The data above shows that the flight delay is very serious at busy airports: Beijing Capital Airport, Shanghai Hongqiao Airport and Guangzhou Baiyun Airport at present, which is shown in Table 2.

Table 2.Statistical table of flight delay of three airports

\begin{tabular}{|l|c|c|c|}
\hline \multicolumn{1}{|c|}{ Name of airport } & $\begin{array}{c}\text { Beijing Capital } \\
\text { Airport }\end{array}$ & $\begin{array}{c}\text { Shanghai Hongqiao } \\
\text { Airport }\end{array}$ & $\begin{array}{c}\text { Guangzhou Baiyun } \\
\text { Airport }\end{array}$ \\
\hline Total landing flight & 81 & 48 & 63 \\
\hline Normal flight number & 57 & 34 & 37 \\
\hline Normal flight percentage & $70.4 \%$ & $70.8 \%$ & $58.7 \%$ \\
\hline Delayed flight number & 24 & 14 & 26 \\
\hline Delayed flight percentage & $29.6 \%$ & $29.2 \%$ & $41.3 \%$ \\
\hline Total takeoff flight & 83 & 58 & 84 \\
\hline Normal flight number & 34 & 37 & 50 \\
\hline Normal flight percentage & $41.0 \%$ & $63.8 \%$ & $59.5 \%$ \\
\hline Delayed flight number & 49 & 21 & 34 \\
\hline Delayed flight percentage & $59.0 \%$ & $36.2 \%$ & $40.5 \%$ \\
\hline
\end{tabular}

Note: a flight is considered on schedule with a delay less than 15 minutes

ii) After optimization:

There are a total of 81 flight landing at Beijing Capital Airport, which only one flight waiting for 15minutes at a time, accounting for $1.23 \%$ of total flights; take-off flights for a total of 83 frame, which 8 flight implement ground-holding, accounting for take-off 9.64\% of total flights, 7 flight waiting for 5 minutes, accounted for $8.43 \%$ of total flights, only one flight waiting for 10minutes, accounting for $1.21 \%$.

Shanghai Hongqiao airport landing a total of 48 flight, which one flight waiting for 5 minutes, account for $2.08 \%$ of total flights; take-off flights for a total of 58 flight, which one flight waiting for 5 minutes, accounting for $1.72 \%$ of total flights.

Guangzhou Baiyun airport landing flight for a total of 63 frame, which 8 implementation of the ground waiting, accounting for $12.70 \%$ of total landing flights, 5 flights waiting for 15 minutes, accounting for 7.94\%;3 flights waiting for 10 minutes ,accounting for $11.90 \%$; take-off flights for a total of 84 flight, which 10 flight in the implementation of the ground waiting, accounting for $11.90 \%$ of total taking-off flights, 4 flights waiting for 15 minutes at a time, accounting for $4.76 \%$ of total taking-off flights, 3 flights waiting for 10 minutes, accounting for 3.57\%,3 flights waiting for 5 minutes, accounting for $3.57 \%$.

\section{Conclusions}

This paper establishes a multi-airport ground-holding strategy model, and verifies the validity of the model through a case study. It is verified by examples that the capacity of the airport can be used effectively by using the ground-holding strategy model in the following aspects.

- Multi-airport ground-holding strategy can eliminate delays, guarantee punctuality, and also minimize the ground waiting time.

- Multi-airport ground-holding strategy also minimizes the ground waiting and delay costs by controlling delays and prioritizing flights of multiple airports. 
In the future research, flight delays due to traffic control and weather reasons should also be included into the model, which will provide a more comprehensive optimization of the air traffic flow.

\section{Acknowledgements}

This research is supported by the National 863 Program (2007AA11Z202) of China.

\section{References}

[1] Peter B.M. Vranas,Dimitris Bertsimas and Amedeo R.Odoni: Operations Research, Vo1.42, No.2, Mach-April1994, 275-291.

[2] Odoni.A.R: Flow Control of Congested Networks. Berlin Springer, 1987, 268-288.

[3]Andreatta G, Brunetta L: Operations Research, 1998, 46(1):57-64.

[4] Brunetta L, Guastalla G and Navazio L: Annals of Operations Research, 1998, 81(1):271-288.

[5] Vranas P B and Odoni A R: Operations Research, 1992, 42(3385-92.):202-202.

[6] Hong D: Design of Adaptive Genetic Algorithm on Single Airport Ground-Holding Policy[C]// International Conference on Transportation Engineering 2007. ASCE, 2015:253-258.

[7]Lili Wang, Qiuli Gu and Zhaoning Zhang: Science and Technology and Engineering, 2013, 13 (20): 5878-5882. (in Chinese)

[8] Ravizza S, Atkin J A D and Burke E K: Journal of Scheduling, 2013, 17(5):507-520.

[9] Weiwei Jiang, Deguang Cui and Xuezhi Shu: Journal of Tsinghua University: Natural Science Edition, 2006, 46 (1): 137-140. (in Chinese)

[10] Shihao Wang, Hongyu Yang, Yuzhen Li, et al: Computer Technology and Development, 2014 (2): 6-9. (in Chinese) 